\title{
Development of a two-tier instrument on simple electric circuits
}

\author{
Lana Ivanjek $\odot,{ }^{1, *}$ Louisa Morris $\odot,{ }^{2,3}$ Thomas Schubatzky $\odot,{ }^{4}$ Martin Hopf $\odot,{ }^{2}$ \\ Jan-Philipp Burde $\odot,{ }^{5}$ Claudia Haagen-Schützenhöfer®, ${ }^{4}$ Liza Dopatka $\odot,{ }^{6}$ \\ Verena Spatz $\odot,{ }^{6}$ and Thomas Wilhelm $\circledast^{7}$ \\ ${ }^{1}$ TU Dresden, Didactics of Physics, Haeckelstraße 3, 01069 Dresden, Germany \\ ${ }^{2}$ University of Vienna, Austrian Educational Competence Centre Physics, \\ Porzellangasse 4, 1090 Vienna, Austria \\ ${ }^{3}$ Pädagogische Hochschule Wien, Grenzackerstraße 18, 1100 Vienna, Austria \\ ${ }^{4}$ University of Graz, Department of Physics Education, Universitätsplatz 5, 8010 Graz, Austria \\ ${ }^{5}$ University of Tübingen, Physics Education Research Group, Auf der Morgenstelle 14, \\ 72076 Tübingen, Germany \\ ${ }^{6}$ TU Darmstadt, Physics Education Research Group, Hochschulstrasse 12, 64289 Darmstadt, Germany \\ ${ }^{7}$ Goethe University, Department of Physics Education Research, Max-von-Laue-Straße 1, \\ 60438 Frankfurt a.M., Germany
}

(Received 9 March 2021; accepted 3 August 2021; published 24 September 2021)

\begin{abstract}
This article reports the development of a two-tier simple electric circuits test (2T-SEC Test). Simple electric circuits are introduced to students early in their school years and are an important part of the physics curriculum all the way to the university level. However, many students do not develop an adequate conceptual understanding of simple electric circuits and especially of electrical voltage. For this reason, six physics education research groups from Germany and Austria started a large study to evaluate and improve middle-school students' conceptual understanding of simple electric circuits. As a first step, we developed the test instrument presented in this article. First, nine semistructured interviews were conducted with middle-school students in Austria. The interviews were transcribed, analyzed and (common) student difficulties with simple electric circuits were identified. Second, based on the results from the interviews and previous research on this topic, an instrument consisting of 25 two-tier multiple-choice items was developed and administered to $N=1568$ middle-school students in Austria and Germany. Third, the data were evaluated using Rasch analysis. The item reliability of the test was 0.99 , while the person reliability of paired scoring was 0.62 and the reliability of separate scoring was 0.75 . The average difficulties of the main concepts regarding simple electric circuits (open and closed circuits, electric current, resistance, series and parallel circuits, and electrical voltage) were calculated and compared. The analysis suggests that the concept of voltage is most difficult for students while distinguishing between open and closed circuits is the easiest.
\end{abstract}

DOI: 10.1103/PhysRevPhysEducRes.17.020123

\section{INTRODUCTION}

Permanent access to electrical energy at any time represents one of the most important developments of human society over the last few centuries. Although electricity and especially the responsible use of electrical energy play an essential role in a world of the 21 st century, only a small proportion of people develop a deeper understanding of the basic electrical quantities such as

\footnotetext{
*lana.ivanjek@tu-dresden.de

Published by the American Physical Society under the terms of the Creative Commons Attribution 4.0 International license. Further distribution of this work must maintain attribution to the author(s) and the published article's title, journal citation, and DOI.
}

current or voltage. This seems astounding, since in most countries students in middle schools and high schools are required to learn about simple electric circuits. In Austria and Germany, for example, simple electric circuits are introduced to most students in 7 th or 8th grade. Corresponding lessons usually last for about 9 to 10 weeks [1] and cover open and closed circuits, electric current, electrical resistance, electrical voltage, and series and parallel circuits [2]. However, simple electric circuits and especially an adequate understanding of voltage are very challenging for most students [3].

To help those students to develop an understanding of electric circuits and in particular of the concept of voltage, Physics Education Groups at the University of Vienna (Austria), the University of Graz (Austria), the University of Frankfurt (Germany) and the Technical University 
Darmstadt (Germany) started a joint design-based research project. In the meantime, the group has expanded to the University of Tübingen and TU Dresden. The overall goal of the project is to evaluate and improve the conceptual understanding of electric circuits in middle school, with the special emphasis on the concept of voltage. Within the project new teaching materials for middle-school students are being developed [4]. However, before evaluating the effectiveness of these teaching materials, a two-tier multiple-choice instrument about simple electric circuits was designed based on previous work [5] and our own research. In this article, we present the development and evaluation of this test instrument, which is suitable for middle-school students and upwards.

\section{LITERATURE OVERVIEW}

\section{A. Student difficulties and misconceptions regarding electric circuits}

There are many different terms, such as "misconceptions," "alternative frameworks," "naive concepts," "phenomenological primitives or $p$ prims" or "children's science," that are being used by researchers to refer to students' difficulties, that are incorrect from the physicist's point of view [6]. However, according to Jung [7] they all mean essentially the same: students are not "unwritten pages" but enter the classroom with an inventory of ideas and beliefs about the physical world. Building on these prerequisites is necessary for an effective learning process, as has been shown by many researchers $[8,9]$.

Students' difficulties can be caused by many different circumstances. Explanations that students give to different physics problems can be interpreted from two different theoretical perspectives: as knowledge as theory [10] and as knowledge in pieces [6,11]. In the first framework student difficulties are seen as a sign of stable alternative conceptions [10] and in the other as a result of on-the-spot, context-dependent activation of cognitive resources $[6,11]$. When considering simple electric circuits, we presume that in middle-school samples both frameworks could occur. Middle-school students are not likely to possess firm alternative ideas related to the concept of voltage, which is abstract and not related to their everyday experience. So, for this purpose, knowledge in pieces framework may be more suitable for the analysis of students' explanations. On the other hand, when we consider the concept of current, students may have some stable elements of cognitive structure, that have been derived from the everyday life (which are, for example, reflected in the expression "the current is used up"). In this paper, the term student difficulties will be used to refer to all student answers and explanations that are incorrect from a physics point of view.

The field of electricity is one of the most researched areas regarding student difficulties. There are many known difficulties concerning simple electric circuits that have been documented by various researchers around the world. Many of these difficulties persist even after the instruction in upper-level university courses [12]. Summarized, the findings from previous research show that students think of current as a substance (e.g., Ref. [13]), that they do not distinguish between the concept of current and the concept of voltage (e.g., Ref. [14]), and that they think, current is "used up" by light bulbs $[9,14]$. Furthermore, they consider the battery as a source of constant current [9,14-16], which leads to the assumption that two bulbs "share" the current, regardless of their position in the electric circuit (e.g., Ref. [17]). Besides these difficulties about the electric current, there are also many known difficulties about the resistance of a resistor in electric circuits. Some students believe that the current increases, if the resistance increases [14] or - the other way around - that the current does not increase, if the resistance decreases [14]. Another basic difficulty concerning resistance is the tendency to focus on the number of elements rather than on their configuration [9]. Other common difficulties are the tendency to reason sequentially or locally rather than holistically $[9,14]$, difficulties with the topological structure, difficulties with the distinction of series and parallel circuits $[9,18,19]$, the concept, that the current passing the light bulb in the electric circuit depends on the position of that element in the circuit $[9,19]$ and the difficulties with superposition of connected batteries [20]. Moreover, many students seem to have difficulties identifying a closed electric circuit [9].

\section{B. Research-based teaching materials for simple electric circuits}

Over the last decades, much thought has been given not only to students' difficulties, but also to how teaching materials can help students overcome these difficulties. For example, the Physics Education Group of the University of Washington has done some extensive research on student misconceptions. In two related articles [9,21], McDermott and Shaffer describe their research-based guide to curriculum development for introductory electricity. As part of their results they developed a collection of research-based teaching materials, which has been published in the form of the two books Tutorials in Introductory Physics [22] and Physics by Inquiry [23]. Zuza et al. [24] also developed research-based teaching materials under a design-based research paradigm for introductory college level. In their material, they focus on differentiating between surface charges and moving charges in cables and students are encouraged to reason about electric currents on the macroscopic as well as on the microscopic level.

Students on the middle-school level, however, often find it difficult that electric voltage refers to two distinct points in an electric circuit. Some researchers tried to address this by introducing electric voltage as the primary concept when analyzing electric circuits while also emphasizing that the 
voltage refers to two points. Psillos, Tiberghien, and Koumara [25], for example, introduce voltage first in their curriculum by measuring it between the terminals of a battery.

Other approaches tried to make use of analogies [26] in order to facilitate understanding of simple electric circuits and voltage in particular. The idea is to make abstract concepts easier to comprehend for students by comparing them to phenomena known from their everyday life or previous experience. However, the effectiveness of teaching approaches, which rely on analogies, is highly dependent on the analogy used. For example, Schwedes and Dudeck [27] argue that when using a water circuit analogy with horizontal water flow in water pipes much time has to be spent on learning the adequate concepts for the water model to the point where the hydrodynamics of the water circuit will constitute a curriculum element on its own.

However, other approaches and studies, where voltage is introduced as potential difference, report a good understanding of circuits [28-30]. For example, an air pressure analogy was used in the CASTLE curriculum [29], which is more compelling to students than the water circuit analogy. This approach was picked up and further developed by Burde and Wilhelm [30] resulting in teaching materials which are based on key ideas of the aforementioned knowledge in pieces perspective on learning [31]. The benefit of using this air pressure analogy is that students typically already show an adequate understanding of air pressure, so time spent on talking about the source domain and compressibility of air can be kept to a minimum. They state that "[...] the air pressure analogy thus represents a promising way to illustrate the relationship between potential difference and current to students in middle school" [30].

\section{Assessment of student difficulties}

Student assessments are a reliable method to detect common student difficulties and-if used in a pre-postdesign - to receive information about the students' learning progress. The results can help teachers respond to present difficulties and adapt their lessons accordingly. In addition, assessments allow comparison of different teaching approaches and to review their effectiveness. In the past, several multiple-choice tests have been developed to identify some of the above-mentioned student difficulties or to compare different teaching approaches. The Determining and Interpreting Resistive Electric Circuit Concepts Test (DIRECT) by Engelhardt and Beichner [16], the Inventory of Basic Conceptions for DC Circuits (IBCDC) by Halloun [32], the Electric Circuits Conceptual Evaluation Test (ECCE) by Sokoloff [33], and a three-tier test instrument developed by Peşman and Eryılmaz [34] are especially worth mentioning. All of them have been developed for introductory college and high school and contain items about current, voltage (potential difference) and resistance, as well as items about series and parallel circuits and about brightness. Likewise, two assessments about simple electric circuits have been developed in German speaking countries: first, the Rhöneck test [14] and second, the assessment from Urban-Woldron [5], which is based on the former. Both have been created for students at lower secondary level aged 13-14 years and include basic concepts about simple electric circuits. However, they do not contain a balanced number of items concerning voltage.

Two-tier instruments are multiple-choice instruments that consist of items with two subquestions (tiers). The first tier consists of a content question and the second tier asks students to choose which alternative best represents their reasoning in the first tier. The advantages of two-tier instruments are that they are easy to administer and that they provide an insight into students' reasoning. Tamir [35] found that the use of reasoning questions when answering multiple-choice questions can be a sensitive and effective way of assessing meaningful learning among students, and that it addresses, to some extent, the limitation of traditional multiple-choice items. The critiques of the two-tier tests are that the students' response to the second tier could be biased by showing the predefined answer options and what the student answers could represent a lack of knowledge rather than a typical alternative conception [36]. Nevertheless, twotier instruments have been successfully used in biology education [37], chemistry education, and physics education research [38].

Although, as pointed out earlier, there are some assessments that also cover the concept of voltage in English, none of them are intended for the middle-school level. This paper therefore aims to close the research gap and to develop a two-tier instrument that can detect student difficulties. It includes items on voltage that can be applied for students aged 13-14. For this purpose, the assessment from Urban-Woldron [5] has been refined and expanded by some items concerning the concept of voltage.

\section{RESEARCH DESIGN AND METHODS}

The development of the test-instrument was orchestrated in three major steps. First, nine semistructured interviews were conducted with middle-school students in Austria. The interviews were transcribed, analyzed, and (common) student difficulties with simple electric circuits were identified. Second, based on the results from the interviews and previous research on this topic [5] an instrument consisting of 25 two-tier multiple-choice items was developed and administered to $N=1568$ middle-school students in Austria and Germany. Third, the data were evaluated using Rasch analysis. 


\section{A. Interviews}

In the first stage of this study, nine semistructured interviews were carried out with students (6 female; 3 male) aged 14-15 years in two different state schools in Vienna, Austria. The aim of this was first to find student difficulties concerning the concept of voltage and thereby to develop new multiple-choice items to supplement the test from Urban-Woldron and, second, to find new distractors for some of the existing items of the test to develop them into two-tier questions, as well as to optimize the test instrument overall.

The students participating in this study had already been instructed about simple electric circuits in the previous year and their self-assessment of their understanding of this topic varied. They had been taught by one of three teachers of different age and experience in education. The interviews were carried out following an interview guide that was based on relevant research on simple electric circuits [5,9,16,32]. The interviews consisted of one introduction question and 12 main questions with up to three sub questions. The students had to answer different questions about simple electric circuits (mostly about voltage) with the help of schematic diagrams. The interviewer lay emphasis on detecting the reasoning behind the students' answers by asking them repeatedly about their explanations. The main topics of the interview questionnaire can be seen in Table I.

The data basis consists of $5 \mathrm{~h}$ of interview material (each interview lasted between 17 and $48 \mathrm{~min}$ ), that was transcribed, carefully analyzed by using a coding system, and the common student difficulties were categorized. The results of the interviews combined with the results of the existing instruments on electric circuits $[5,16,32]$ represented the basis for developing the first version of the new two-tier instrument on simple electric circuits.

\section{B. Two-tier instrument}

The first version of the two-tier instrument consisted of 30 two-tier items. The pilot study was conducted on 228 students aged 14-15 from Vienna and Graz (both Austria), and Frankfurt (Germany). The students had been instructed on simple electric circuits in the previous school year. Rasch analysis of data was conducted and based on the results some items were revised and simplified.

The revised instrument was administered to $N=1568$ middle-school students (49.5\% male) in grades 7 and 8 from 38 different schools in Austria and Germany. Students were tested directly after instruction on simple electric circuits. The test was divided into two test booklets which were linked with 12 shared items. Each booklet had 21 items and the whole test had 30 items. The allocated time for taking the test was $45 \mathrm{~min}$, and students were able to complete the test in that time. Rasch analysis was conducted again and 5 items were removed from the test because of their misfit values.

The final version of the instrument (2T-SEC test) consists of 25 two-tier items. The items are divided in five groups that represent five different concepts of simple electric circuits. Eight experts from PER groups in Austria and Germany assigned each of the items to one of these five concepts. These include open and closed circuits, electric current, electric resistance, series and parallel circuits, and the concept of voltage. All five concepts, as well as their description and related items from the instrument, are presented in Table II.

TABLE I. Main topics of the interview questionnaire.

\begin{tabular}{|c|c|c|}
\hline Concept & Questions & Example of main question \\
\hline Voltage in open and closed circuits & $1,3,4$ & $\begin{array}{l}\text { A } 6 V \text { bulb and a switch are installed into a circuit. Is the electric } \\
\text { circuit closed? Explain your answer. (Question } 1 B, 1.1 \text { ) }\end{array}$ \\
\hline Identifying series and parallel circuits & $2,(3,4,10)$ & $\begin{array}{l}\text { Which of the shown circuits is a series circuit? Explain your answer. } \\
\text { (Question 3A, 3.1) }\end{array}$ \\
\hline Voltage in series and parallel circuits & $3,4,10$ & $\begin{array}{l}\text { The circuit shown consists of a } 6 \text { V battery, a switch and two identical } \\
6 \text { V light bulbs. What is the voltage } V_{1} \text { across the light bulb } 1 \text { ? } \\
\text { Explain your answer. (Question } 2 A)\end{array}$ \\
\hline $\begin{array}{l}\text { Voltage in series and parallel circuits } \\
\text { with multiple batteries }\end{array}$ & 5,9 & $\begin{array}{l}\text { The circuits shown below each consist of one or two } 3 \text { V batteries and } \\
\text { a } 6 \text { V light bulb. Which of the circuits has the highest voltage across } \\
\text { the light bulb? Explain your answer. (Question 5) }\end{array}$ \\
\hline $\begin{array}{l}\text { Electric current in series and parallel } \\
\text { circuits }\end{array}$ & 12 & $\begin{array}{l}\text { The circuit shown consists of a } 6 V \text { battery and two identical light } \\
\text { bulbs. Compare the current through the light bulbs } L_{1} \text { and } L_{2} \text {. } \\
\text { (Question } 12 \mathrm{~A}, 12.1 \text { ) }\end{array}$ \\
\hline $\begin{array}{l}\text { Brightness and voltage of light bulbs } \\
\text { in circuits with different batteries or } \\
\text { different light bulbs }\end{array}$ & $6,7,8$ & $\begin{array}{l}\text { Circuit } 1 \text { consists of a } 3 \text { V battery and a } 3 V \text { light bulb. In circuit } 2 \text { the } \\
\text { battery is replaced by a } 9 \mathrm{~V} \text { battery. Compare the voltages across } \\
\text { the light bulbs for circuits } 1 \text { and } 2 \text {. (Question 7, 7.2) }\end{array}$ \\
\hline $\begin{array}{l}\text { Brightness and voltage of light bulbs } \\
\text { in a circuit with and without } \\
\text { branches }\end{array}$ & 11 & $\begin{array}{l}\text { The circuit shown consists of a } 6 V \text { battery and three identical light } \\
\text { bulbs. What are the voltages } V_{1}, V_{2}, V_{3} \text { across the light bulbs? } \\
\text { Explain your answer. (Question } 11 \mathrm{~A}, 11.2 \text { ) }\end{array}$ \\
\hline
\end{tabular}


TABLE II. Five concepts and related items.

\begin{tabular}{|c|c|c|}
\hline Concepts & Description & Items \\
\hline Open and closed circuits & Students differentiate between open and closed circuits. & $1,2,11$ \\
\hline Electric current & $\begin{array}{l}\text { Students identify that the current is constant and the same at every } \\
\text { point in a series circuit. Also, they recognize that the sum of the } \\
\text { currents flowing through each branch is equal to the total current } \\
\text { flowing through the circuit. }\end{array}$ & $9,15,18,22,23$ \\
\hline Electric resistance & $\begin{array}{l}\text { Students recognize that the net electric current is inversely } \\
\text { proportional to the net electric resistance of a resistor when the } \\
\text { voltage of the battery is constant. }\end{array}$ & $4,5,16,24$ \\
\hline Series and parallel circuits & $\begin{array}{l}\text { Students distinguish between series and parallel circuits based on the } \\
\text { schematic diagram of the circuit. }\end{array}$ & $6,10,13,20$ \\
\hline Voltage & $\begin{array}{l}\text { Students determine the voltage across two different points in a circuit } \\
\text { correctly. Also, they infer the brightness of a light bulb from the } \\
\text { voltage across it. }\end{array}$ & $3,7,8,12,14,17,19,21,25$ \\
\hline
\end{tabular}

An example of one item is in Fig. 1 and the whole instrument can be found in the Supplemental Material [39]. The instrument can also be divided into basic test items (Items 1-11) and more advanced items (Items 12-25).

As can be seen in Fig. 1, the first tier of each item asks about one parameter in the electric circuit (in this case about voltage) and the second tier asks students to explain their reasoning. Specific combinations of answers from the first and the second tier reflect some of the student difficulties with simple electric circuits.
The data were analyzed with the Winsteps program for Rasch analysis [40]. The Rasch model is a probabilistic model that describes what happens when a student interacts with the test item and it converts the counts (raw scores) to person ability measures. This gives the user linear measures of item difficulty and person ability expressed on the same scale. The model assumes that the test is unidimensional, which means that all items probe only the measured variable (in our case student understanding of simple electric circuits). The linearity of measures is very

\begin{tabular}{|c|c|l|}
\hline \multicolumn{2}{|c|}{ Item 12 } & Consider the following circuit. \\
(a) & & What is the voltage between points 1 and 2 ? \\
\hline A & $\square$ & There is no voltage between points 1 and 2. \\
\hline B & $\square$ & The voltage between points 1 and 2 is $6 \mathrm{~V}$. \\
\hline C & $\square$ & The voltage between points 1 and 2 is less than $6 \mathrm{~V}$. \\
\hline (b) & & Why? Choose the statement that best fits your reasoning. \\
\hline A & $\square$ & The voltage decreases as the distance to the battery increases. \\
\hline B & $\square$ & There is no voltage in an open circuit. \\
\hline C & $\square$ & Points 1 and 2 are directly connected to the terminals of the battery. \\
\hline D & $\square$ & There is no voltage in an open circuit without a resistor. \\
\hline
\end{tabular}

FIG. 1. Example of an item on electric voltage. 
important, because it enables comparisons and statistical studies. Therefore, the Rasch model has a wide application in physics education research [41-46]. For a more detailed introduction to the Rasch model see, for example, Refs. [47-49].

In the course of the analysis of the 2T-SEC test, item reliability, person reliability, the distribution of items and persons across the latent trait (Wright map) and fit statistics were evaluated to assess the fit of the data to the model [48]. The summary statistics provide two reliability values: person reliability and item reliability. The person reliability value can be interpreted similarly to Cronbach's alpha, meaning that values closer to 1 indicate more internally consistent measures. The item reliability gives information about the reproducibility of item difficulty hierarchy. The distribution of the items and persons across the latent trait (Wright map, also known as item-person map) represents the plot of both persons and items along the same logit scale. The Wright map enables the visualization of the targeting of the test to the sample, as well as the targeting of individual items to persons and provides information on how well the persons and items are distributed along the latent trait. In a well-constructed instrument the width of the target population ability distribution matches with the width of the distribution of test items and there are no larger gaps between the item difficulties [49]. Rasch analysis also reports two fit statistics: infit and outfit mean square statistics (MNSQ). Large outfit values indicate that the person whose ability is far from the item difficulty answered unexpectedly to the item. For items with difficulties that are much higher than the person's ability, large outfit values could be a result of the person simply guessing the correct answer. Large infit values indicate that the persons whose ability is close to item difficulty have not responded in a way, which is consistent with the model. Since the MNSQ outfit values are sensitive to outliers, priority is given to MNSQ infit values when analyzing item misfit. Items with infit and outfit values in between 0.5 and 1.5 have reasonable fit of the data to the model [47], but items with significant infit and outfit (greater than 1.3) should be inspected more to find the reasons for their misfit [50].

Two different types of analysis were performed: separate scoring and paired scoring. In a separate scoring model, each tier was treated as a separate question and one point was awarded if the answer on that tier was correct and zero points if it was incorrect. In paired scoring, students received one point if the answers on both tiers were correct and zero points if one of the tiers were incorrect. Both scoring models were analyzed with the Winsteps program [40] in order to see how they match with the Rasch model.

In addition to the Rasch analysis, the combination of different student answers on two tiers of one question were analyzed in order to assess the prevalence of different student difficulties with simple electric circuits.

\section{RESULTS AND DISCUSSION}

\section{A. Results from the interviews}

The results of the interviews show that all interviewed students had major difficulties with the understanding of simple electric circuits. This manifested itself in basic errors with the understanding of an open and closed electric circuit or confusing series with parallel circuits, to errors on a more advanced level, such as the prognosis of the voltage across a light bulb in an electric circuit with more than one battery. The interview material was analyzed and narrowed down to five student difficulties concerning voltage that were repeating through several interviews.

Three of the five student difficulties from the interviews confirm known student difficulties from past research. The other two were, to our knowledge, previously not reported, but show up certain similarities to known misconceptions:

\section{Voltage depends on the distance from the battery}

During the interviews for this study, some students stated that the voltage between the terminals of a light bulb depends on the position of that element in the electric circuit.

For example, in a series circuit, as shown in Fig. 2, students assumed that the voltage across the light bulb nearer to the battery was higher than the voltage across the light bulb further away from the battery. One student explained "I believe the voltage across light bulb 1 is higher than across light bulb 2 because the current has a longer way to go to light bulb 2" (Interview 1, question $3 \mathrm{~A})$. The student assumes that the voltage decreases the further away it is positioned from the battery in the circuit. Another student explained the reverse idea when he was questioned about the series circuit in Fig. 3: "I need more force to make this light bulb [between 3 and 4] shine. Therefore, I think a higher voltage is necessary" (Interview 8, question 3A). According to this student, the voltage across the second bulb must be higher than the voltage across the first one due to the order in which they were connected.

A related concept was described by McDermott and Shaffer [9]. They found that some students think the direction of current and the order of the element in an electric circuit matter. Therefore, they believe that light bulbs shine brighter if the current does not have to pass

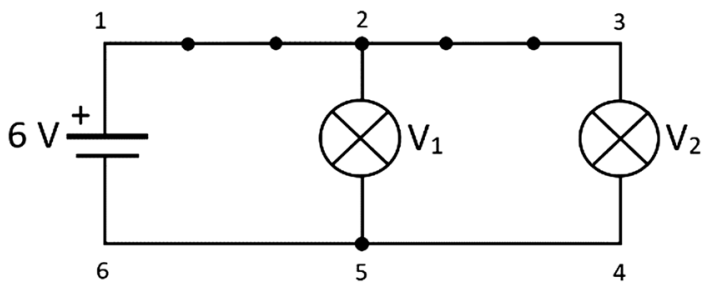

FIG. 2. Question 4. 


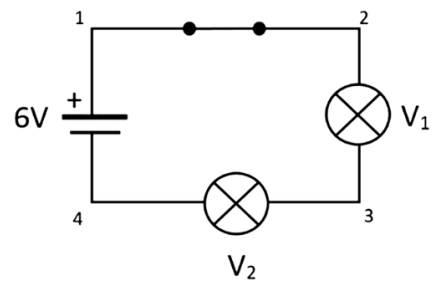

FIG. 3. Question 3A.

through another light bulb before. Similar results could be found by Heller and Finley [19].

\section{Voltage is used up by the light bulb}

The belief that the current is consumed by a light bulb is a known misconception [5,9,14]. During the interviews, a variation of this misconception could be found. Some students assumed that the light bulbs "use up" the voltage. One student addressed this idea as follows: "The voltage is used up by the light bulb here. There is a lot less voltage than between the points 4 and 3 because the light bulb uses up a lot of the $6 \mathrm{~V}$ [terminal voltage]" (Interview 4, question 1C). This difficulty appeared in three of the nine conducted interviews. A reason for this could be the variation of the common misconception mentioned above.

\section{The lack of differentiation between the concept of voltage and the concept of current}

This is the second student difficulty that has been thoroughly described by previous research [14] and could be confirmed by this study. Most of the interviewed students used the terms voltage and current synonymously. They repeatedly demonstrated their lack of a distinct definition of the concept of voltage. One student gave the following answer to the question which voltage was applied to the light bulb in the electric circuit shown in Fig. 4: "It depends on how much voltage is being used up. Approximately 2-4 V would flow through the light bulb" (Interview 6, question 1C). This student obviously mixed up current and voltage since he used the verb "flow" to refer to voltage.

\section{Voltage has a constant value}

Some students believe that the voltage has a constant value throughout the circuit, regardless of the connection of the bulbs within the electric circuit. For example, in

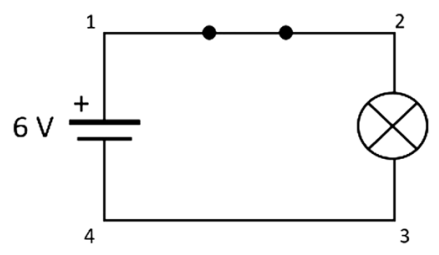

FIG. 4. Question 1C.

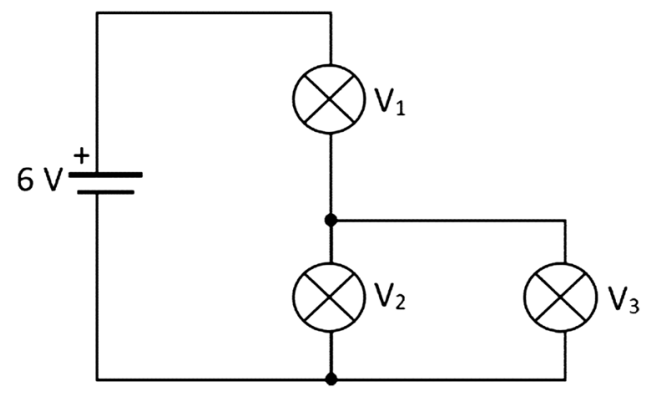

FIG. 5. Question 11A.

question 11A students were asked how bright the light bulbs in Fig. 5 would shine and what voltage they expected across each light bulb.

One student claimed that "they [the light bulbs] will shine equally bright, since they are connected in parallel to each other." Furthermore, this student stated that the voltage across the light bulbs must be "(...) $2 \mathrm{~V}$ each, since it [the voltage] is equally distributed." (Interview 4, question 11A). This idea was assumed by four of the nine interviewed students. It is possible that this student difficulty is linked to the lack of differentiation between the concept of voltage and the concept of current as well as a confusion of series and parallel circuits.

\section{Confusion of series and parallel circuits}

Problems with the topological structure of electric circuits are common $[18,19]$. During the interviews, it became clear that many of the interviewed students had major difficulties identifying series and parallel circuits. In particular, three difficulties were found among the answers of the interviewed students.

(a) In a series circuit, the light bulbs must be installed directly opposite each other (Fig. 6, circuit 2 and 3).

(b) In a series circuit, the light bulbs must be installed directly next to each other along a wire (Fig. 6, circuit 1).



FIG. 6. Question 2A. 
(c) In a parallel circuit, the light bulbs must be installed directly opposite each other (Fig. 6, circuit 2 and 3).

The students who presented ideas consistent with one of these argumentations had a wrong idea about the distinguishing features of series and parallel circuits. Light bulbs can, in fact, be placed at different positions in both series and parallel circuits. Ideas (a) or (c) limit the definition of series or parallel circuits, respectively, to examples where light bulbs are arranged opposite of each other (e.g., Fig. 6, series circuit 2 or parallel circuit 3) but exclude other cases (like series circuits 1 and 4 in Fig. 6). Similarly, idea (b) limits the definition of series circuits to examples where light bulbs are arranged directly next to each other (e.g., Fig. 6, circuit 1) but excludes cases like circuits 2 and 4 in Fig. 6.

This confusion between series and parallel circuits becomes clear in the following explanation by a student who was asked which of the circuits in Fig. 6 represented a series circuit. His answer was "Next to the series circuit there is also the parallel circuit (...). In circuit 1 the light bulbs are not positioned parallel to each other, they are next to each other. But in circuit 2, I am not sure. (...) because they [the light bulbs] are positioned opposite each other (...)" (interview 5, question 2A).

\section{B. Test analysis}

In order to evaluate the functioning of the two-tier $2 \mathrm{~T}$ SEC test instrument, summary statistics, item-fit statistics, and Wright maps were inspected for the paired and separate scoring model.
As a first step, the item-fit statistics for all 30 items was examined for both scoring models. All MNSQ infit values were between 0.5 and 1.5 for both scoring models, but five items had MNSQ outfit values greater than 1.5. Four of those five items were excluded from the test for further analysis. These four items were advanced items and one was a basic item. The fifth item with a big outfit was left in the test because the most likely reason for the high outfit value was the graphical representation of the answer options in the printable version of the test. As can be seen in Fig. 7, the wrong answer and wrong reason were placed just under the image showing the closed circuit in which the light bulb would glow. This probably caused some high ability students to unexpectedly fail on this item, even though it is the easiest item in the test.

In a further step, another item was excluded from the test because the experts' rating could not unambiguously assign the item to only one of the given concepts (open and closed circuits, electric current, resistance, series and parallel circuits and voltage). The remaining 25 two-tier items were used for further analysis. The bubble charts of MNSQ infit for both scoring models for the remaining 25 items are presented in Figs. 8(a)-8(b). A bubble chart is one way of visualizing the fit of the test items [48]. It is a graph of item difficulty (vertical axis) vs MNSQ item infit (horizontal axis). Each item in the chart is represented with a circle, whose size is proportional to the standard error of the item's calibration. The horizontal distance of the circles form the expected MNSQ fit value of 1 and indicate how well each item fits to the model. Ideally, the items should be as close

\section{Item 1}

A light bulb and a closed or open switch are installed in each of three circuits.

(a) In which of the circuits will the light bulb light up?

1)

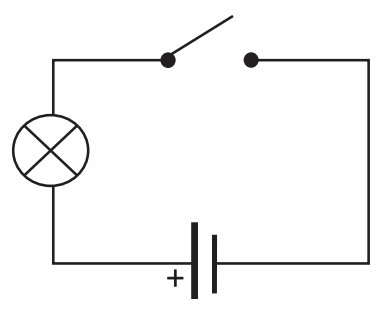

In circuit 1 and 2
2)

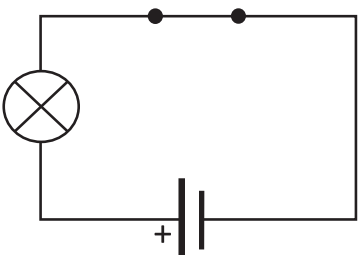

In all circuits
3)

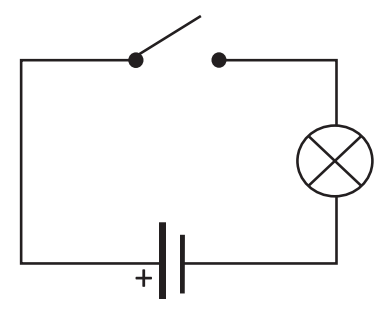

In circuit 2

(b) Choose a statement that best fits your reasoning.

The light bulb always lights up
The light bulb must be installed before the switch, regardless of whether it is open or closed.

FIG. 7. Representation of Item 1 in test booklets. 

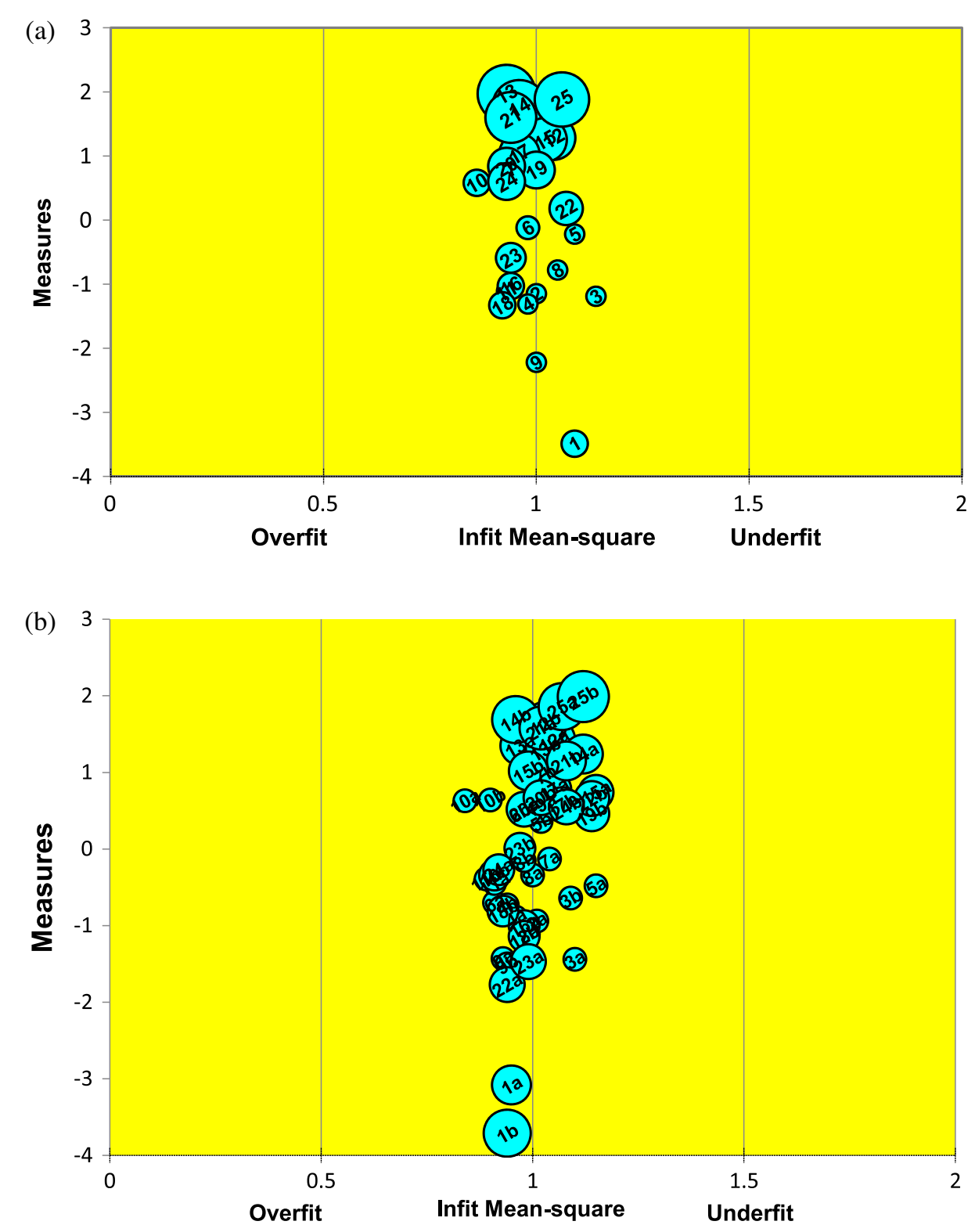

FIG. 8. (a) Bubble-chart for MNSQ Infit values for paired scoring. (b) Bubble-chart for MNSQ Infit values for separate scoring.

as possible to the central axis of the chart, which is in this case true for the infit values. The vertical axis represents the difficulty of the items expressed in the logits. The item entry table with all item parameters can be found in Supplemental Material [39].

Next, the item and person reliability were inspected. With both scoring models, the item reliability was 0.99 . This indicates that item parameters can be easily separated. However, it must be added that the item reliability is usually high with large sample sizes. Person reliability was 0.62 for paired scoring and 0.75 for separate scoring, and the person separation indexes were 1.29 and 1.73 , respectively. These values may be considered acceptable [47], but there are some limitations in obtaining reliable person measures. The mean item difficulty is set to zero logits within Rasch analysis and the mean person ability was -1.46 for paired scoring and -0.40 for separate scoring, which indicates that the test was too difficult for this sample.

To further investigate the distribution of items and persons, Wright maps for paired and separate scorings were constructed as depicted in Fig. 9. The maps show the distribution of persons according to their ability and distribution of items according to their difficulty along the same axis with scale in logit. The persons are distributed on the left side of the axis and the items on the right side. The people with lower abilities and the easier items are closer to the bottom of the map and the people with higher abilities and the items that are more difficult are closer to the top of the map. The evaluation of the map reveals that the test was overall very difficult for 


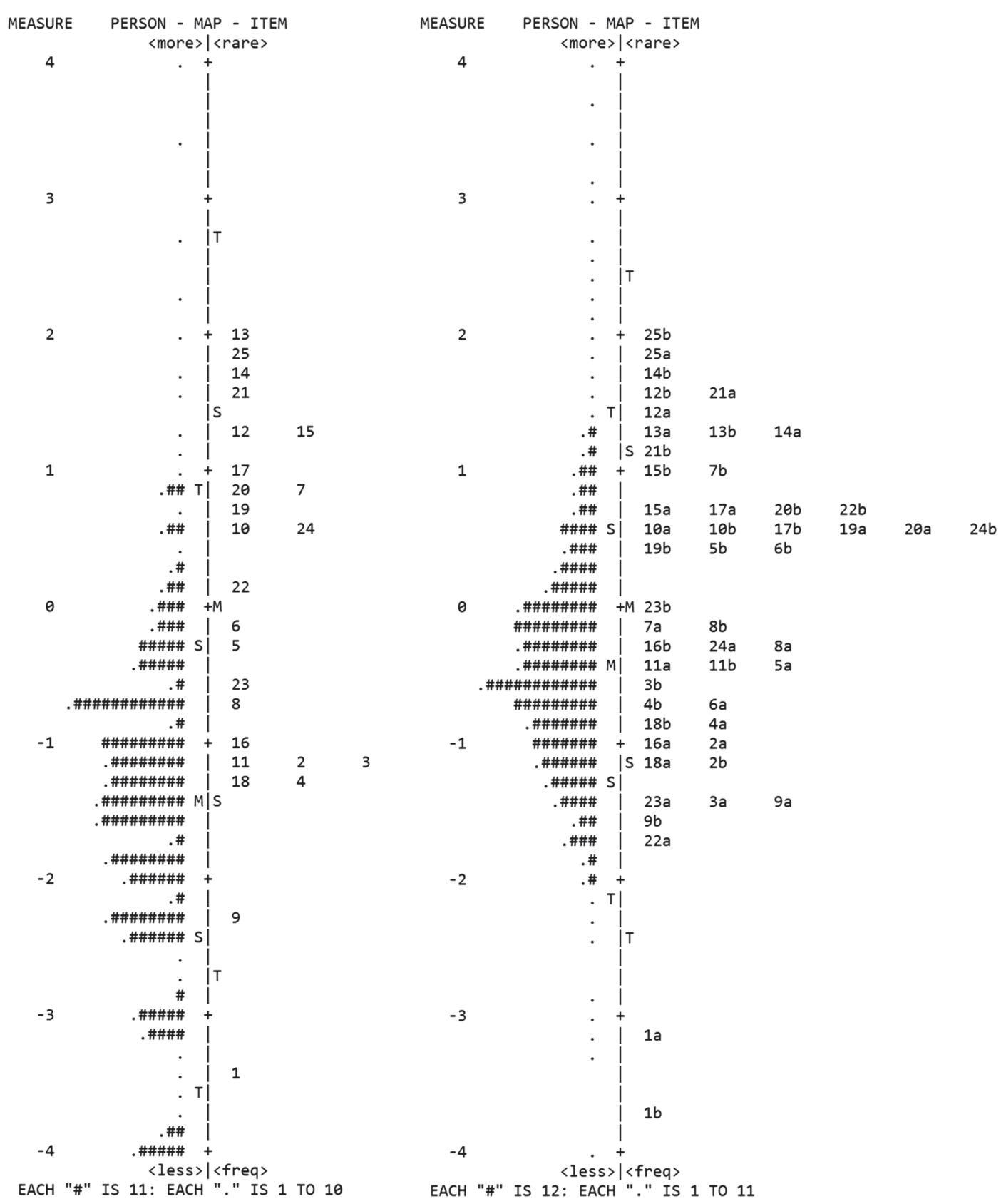

FIG. 9. Wright map for paired (left) and separate scoring (right). $M$ denotes the mean of each distribution.

middle-school students. The comparison of different scoring models shows that the test was more difficult in a paired scoring model than in a separate scoring model. The width of the test with the separate scoring is adequate for most of the students-there are only eleven students with abilities outside the range of the test. In the middle and upper part of the item's distribution, there are many items that are very close in difficulty.

Voltage items and items connected with series and parallel circuits are positioned in the upper part of difficulty distribution, whereas the items asking about open and closed circuits and about electric current are at the bottom of distribution. When separate scoring is used, both tiers of the same question usually have similar difficulties (with the exception of items $3,7,16,22,23$, and 24 , where the second tier is more difficult).

Each scoring method produced a different set of measures of students' understanding of simple electric circuits. These measures were cross-plotted and it can be seen that cross-plots of measures for each student suggest that the measures were largely the same within the limits of their uncertainties as illustrated for two scoring methods in Fig. 10.

A cross-plot of the person measures indicates that both scoring methods seem to produce statistically indistinguishable results regarding person measures. However, 


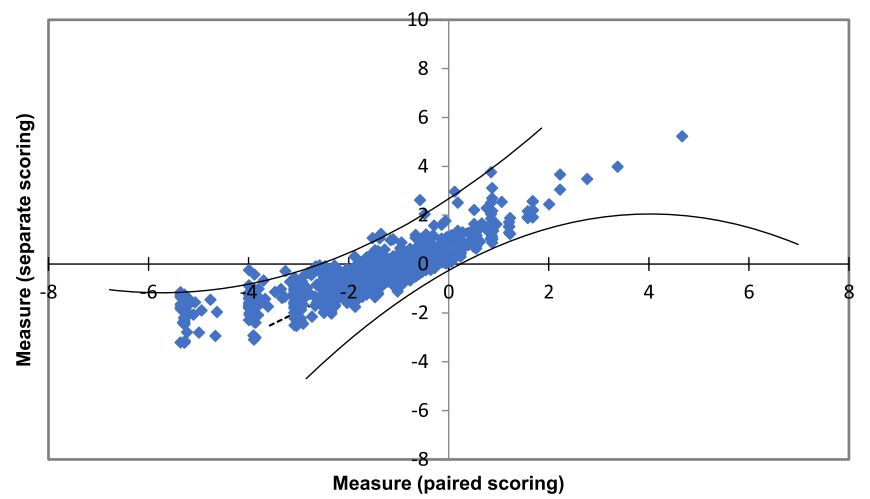

FIG. 10. Cross-plot of persons measures when the test was scored with a separate and paired model. The black lines in the plot represent $95 \%$ confidence intervals.

there are still some advantages and disadvantages of each model. The advantages of the separate scoring model are a larger number of items, a better targeting on the sample, and consequently, a better person reliability. The combination of answers on the first and second tier, obtained through separate scoring, give an insight into the most common student difficulties. Disadvantages of the separate scoring model are the reward of possible guesses and a high dependency of the items. In contrast, paired scoring strongly reduces guessing, but the number of items is significantly reduced and some information may be lost.
Some studies have investigated this issue of scoring on the Lawson test of scientific thinking [51], but came up with inconclusive results which scoring model to use. As each scoring model has its advantages, for further analysis we have decided to use the separate scoring model.

As a next step, the average difficulties were calculated for five different concepts (open and closed circuit, electrical current, electrical resistance, parallel and series circuits and concept of voltage) and graphically represented in Fig. 11. As the average difficulty in Rasch analysis is set to zero, positive values for item difficulties suggest that the items were more difficult than the average and negative values that the items were easier than the average. Error bars represent the level of dispersion of item difficulties from the average difficulty. Figure 11 shows that the distinction between series and parallel circuits and the concept of voltage were the most difficult for the students, while open and closed electric circuits were the easiest. The concepts of electrical current and electrical resistance were easier than average, but still more difficult than the distinction between open and closed circuits.

In order to inspect further test functioning, the DIF (differential item functioning) was inspected. We were interested to examine if the items work the same for male and female respondents. In the Rasch model, we want all items to work as a ruler and for that reason the ordering and spacing of items should not change as a function of

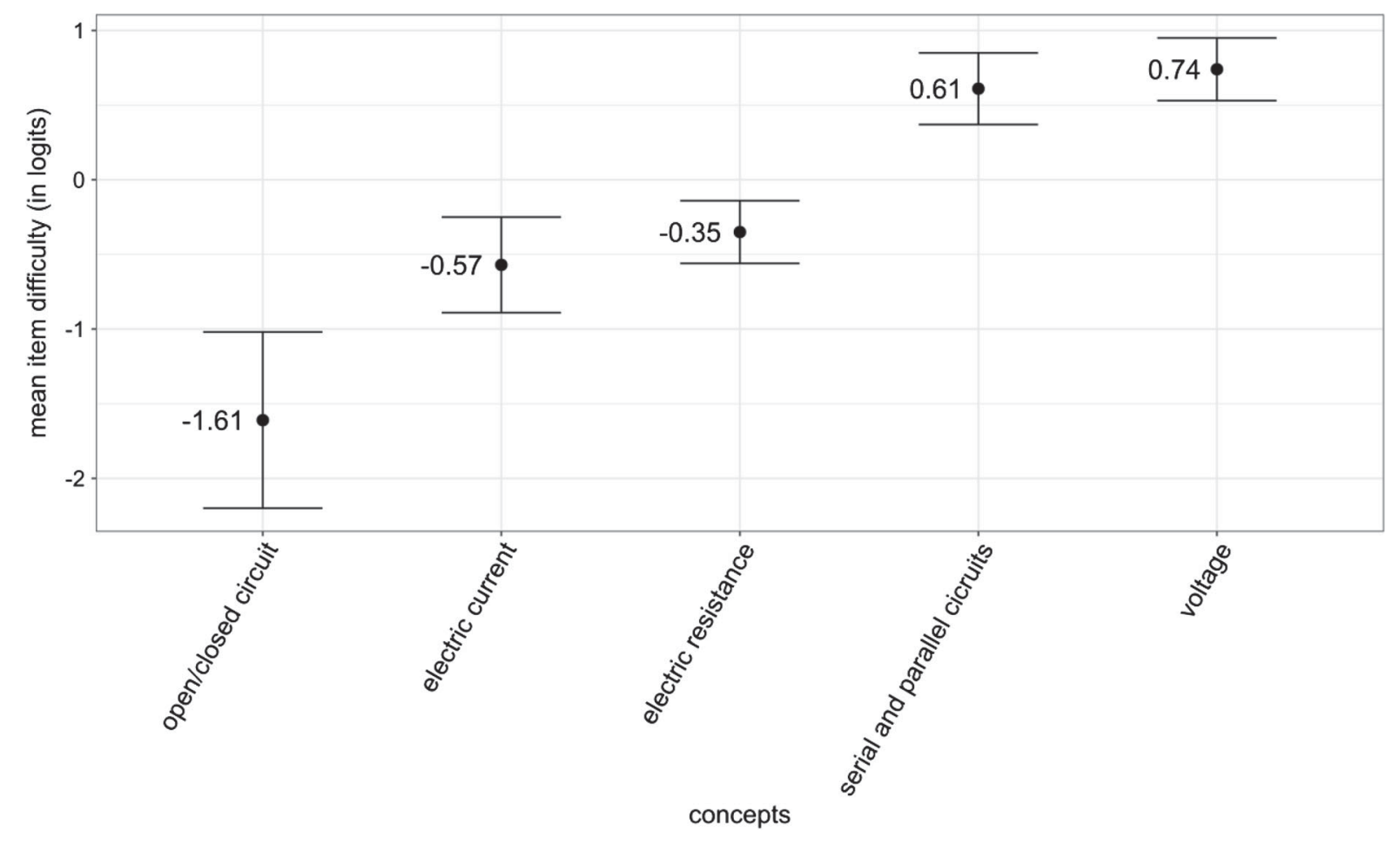

FIG. 11. Average difficulties of different key concepts of electric circuits based on the calculation of the average item difficulty of the items corresponding to each concept. The error bars indicate the combined uncertainties of each average value computed as $\mathrm{CE}=\frac{1}{4} \sqrt{\mathrm{SEM}^{2}+\mathrm{SE}^{2}}$, where SEM is the standard error of the mean and SE is the average Rasch standard error. 


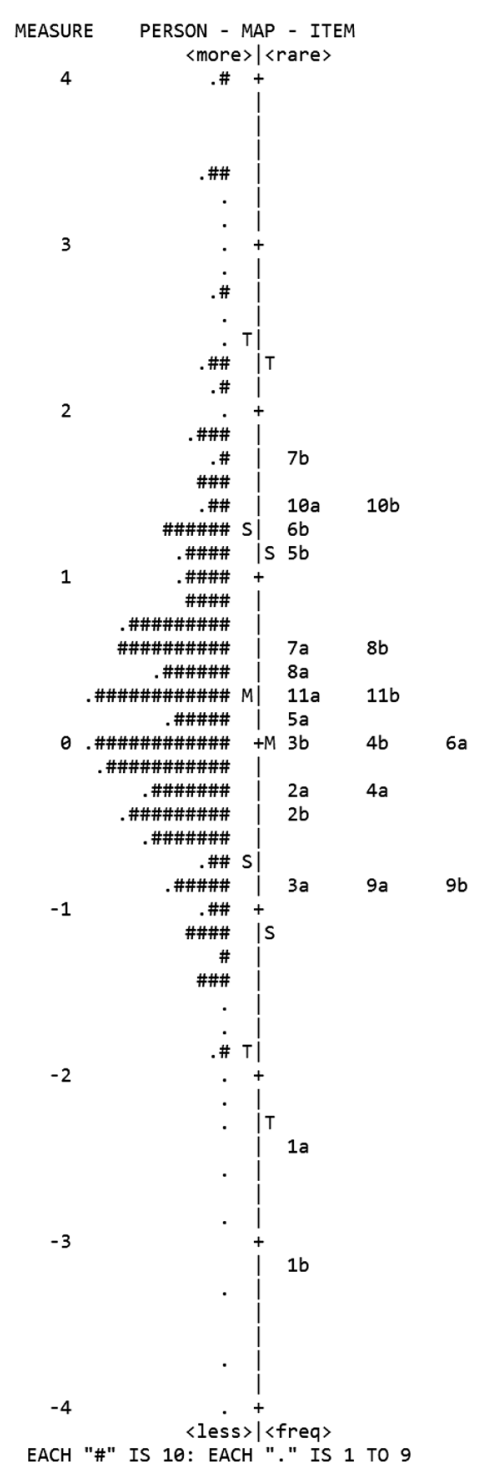

FIG. 12. Wright map for basic items. subgroup, even if the test is overall easier for one sample. The analysis of the magnitude of the difference in the location of the item along the construct for the two groups showed that all values were above the threshold of 0.05 , which suggests that DIF did not occur as a function of gender [47] and that the items show the same behavior for both samples of students.

In the next step, the set of 11 basic items was analyzed (Questions 1-11). Item reliability for those items is 1.00 and the person reliability 0.70 . A Wright map was also generated and presented in Fig. 12. It can be noted that the targeting of the basic items on this sample is much better than the targeting of the whole test. Even the width of the basic items is adequate for most students-about $10 \%$ of tested students have abilities outside the range of item difficulties of basic items. Basic items could be used as a pretest or with a sample where voltage and series and parallel circuits are not covered in great depth.

\section{Test and student difficulties}

In addition to analyzing the functioning of the test with Rasch analysis and analyzing average difficulties for the five concepts in the test, students' most common difficulties were analyzed. The second tier of each question was constructed to reflect the most common student explanations in interviews and student difficulties found in the literature, and some combinations of answers to first and second tier reflect the most common difficulties with simple electric circuits. An example of three student difficulties with the concept of voltage, as well as the item number and the combinations of answers are given in Table III. The third column in the table presents the percentage of students who have selected that answer combination and the last column presents the percentage of students who have consistently showed the same difficulty throughout all items. Other student difficulties

TABLE III. Three student difficulties with the concept of voltage and the items and answer combinations that help to detect those.

\begin{tabular}{lccc}
\hline \hline Student difficulty & Items and answer combination & $\%$ of students & $\%$ of students through all questions \\
\hline Voltage depends on the distance from & Item 7; BA & $4 \%$ & $0 \%{ }^{1}$ \\
the battery & Item 12; CA & $2 \%$ & $3 \%$ \\
& Item 14; AB & $2 \%$ & $2 \%$ \\
The lack of differentiation between the & Item 17; BD $21 ;$ AD & $64 \%$ & $5 \%{ }^{2}$ \\
concept of voltage and the concept & Item 12; AB, AD & $19 \%$ & $2 \%$ \\
of current & Item 14; CA, DA $17 ;$ AE, CE, DE & $7 \%$ & $1 \%$ \\
Voltage is used up & Item 21; AD & $3 \%$ \\
\hline \hline
\end{tabular}

${ }^{1}$ From the students that answered more than 1 item. Note, that the test was divided into two booklets and not all the students answered all the items.

${ }^{2}$ From the students that answered Items 12, 14, and 17. 
and the in-depth analysis of answer combinations will be reported in a subsequent paper.

As can be seen from the table, the percentage of students who have chosen the combination of answers that correspond to typical student difficulties varies depending on the question. This analysis suggests that student reasoning is incoherent and highly dependent on the exact wording of the item. It also corresponds to the fact that the test was hard for most of the students and that they were using different ad hoc ideas when answering different questions related to the concept of voltage. These results coincide with the results from Engelhardt and Beichner who also found that students showed different misconceptions depending on the problem presented [16].

\section{CONCLUSION}

In this study, we have attempted to construct a simple electric circuits inventory (2T-SEC-Test) that could be used with middle-school students and that covers the concept of voltage. The novelty of our test instrument rests in the fact that it is a two-tier test, with a clear attribution of each item to one of five core concepts regarding introductory electricity, and a balanced number of items distributed over those five concepts. The Rasch analysis of the two-tier instrument on simple electric circuits showed a rather good functioning of the test items. Only item 1 deserves further inspection and possibly revision. Our presumption is that the misfit of that item is related to the bad representation of the item in the printed version of the test (see Fig. 7). However, the instrument was not well targeted to our sample of middle-school students in 7 th and 8 th grade. The mean of the distribution of student abilities was about one and a half logit for paired scoring and half of logit for separate scoring below the mean of the distribution of item difficulties indicating that the test was too difficult for our sample. The lack of easier test items resulted in a lower person reliability, especially when the paired scoring model was used. Nevertheless, we have decided to keep some more difficult items in the test as it is also used in the intervention group, which is taught based on a new curriculum that aims to improve students' understanding of simple electric circuits, especially the concept of voltage. The short version of the test containing only 11 basic items had much better targeting to our population. The test instrument can hence be used in a wide variety of scenarios: it can be implemented as a whole, but it is also possible to use only the set of eleven basic items, depending on the sample.

Our findings suggest that the concept of voltage and the distinction between series and parallel circuits are most difficult for most students, while students find it comparatively easy to distinguish between open and closed circuits. This finding is consistent with previous studies that also found that students do not develop the functional understanding of the concept of voltage $[9,14,52]$. The order of five concepts related to simple electric circuits by difficulty might help instructors to put more emphasis on these concepts in their teaching in order to help students to develop a better understanding of simple circuits. It also indicates a learning progression of different topics related to simple electric circuits.

The analysis of the combination of student answers on both tiers of the different items, furthermore, revealed many interesting alternative conceptions, which will be presented in a separate paper. However, since the main purpose of the test instrument is to also assess students' understanding of voltage, it was exemplarily shown that the instrument with its two-tier structure can detect alternative conceptions regarding the concept of voltage. The analysis of combinations of student answers, related to different difficulties with voltage, suggested that middle-school student reasoning about voltage is very fragmented and is activated differently throughout different questions. The observed inconsistency of student answers seems to support the knowledge-in-pieces framework and the fact that after regular classes students have not developed a functional understanding of the concept of voltage.

We therefore believe it is essential that voltage plays a prominent role in physics lessons even at the middle-school level. In particular, students should develop a qualitative understanding of voltage as a quantity that refers to two points in a circuit and that acts as the cause of the current [30]. An important implication for physics teaching is that we should work more on building the models and student reasoning, and not only to provide simple solutions to specific problems. That becomes even more important when we consider the concept of voltage, where most of the middle-school students did not develop any understanding.

\section{ACKNOWLEDGMENTS}

Open Access Funding is provided by the Publication Fund of the TU Dresden.
[1] T. Schubatzky, Das Amalgam Anfangs-Elektrizitätsunterricht. Eine multiperspektivische Betrachtung in Deutschland und Österreich (Logos Verlag, Berlin, 2020), Vol. 299, https://doi.org/10.30819/5159.
[2] T. Schubatzky, M. Rosenberger, and C. Haagen-Schützenhöfer, Content structure and analogies in introductory electricity chapters of physics schoolbooks, Phys. Educ. 54, 065023 (2019). 
[3] D. M. Shipstone, C. v. Rhöneck, W. Jung, C. Kärrqvist, J.-J. Dupin, S. Johsua, and P. Licht, A study of students' understanding of electricity in five European countries, Int. J. Sci. Educ. 10, 303 (1988).

[4] C. Haagen et al., Using the electron gas model in lower secondary schools-A binational design-based research project, in Concepts, Strategies and Models to Enhance Physics Teaching and Learning, edited by E. McLoughlin and P. van Kampen (Springer International Publishing, Cham, 2019), p. 3; J. Lavonen et al., Science education research: Engaging learners for a sustainable future, in Proceedings of ESERA (University of Helsinki, Helsinki, Finland, 2015), ISBN: 978-951-51-1541-6.

[5] H. Urban-Woldron and M. Hopf, Development of a diagnostic instrument for testing student understanding of basic electricity concepts, Z. Didaktik der Naturwissenschaften 18, 201 (2012).

[6] A. A. diSessa, Toward an epistemology of physics, Cognit. Instr. 10, 105 (1993).

[7] W. Jung, in Schülervorstellungen in der Physik. Festschrift für Hartmut Wiesner, edited by R. Müller (Aulis-Verl. Deubner, Köln, 2011), p. 15.

[8] R. Duit, Alltagsvorstellungen berücksichtigen, Praxis der Naturwissenschaften Physik 6, 7 (1993).

[9] L. C. McDermott and P. S. Shaffer, Research as a guide for curriculum development: An example from introductory electricity. Part I: Investigation of student understanding, Am. J. Phys. 60, 994 (1992).

[10] K. A. Strike and G. J. Posner, Conceptual change and science teaching, Eur. J. Sci. Educ. 4, 231 (1982).

[11] D. Hammer, A. Elby, R. E. Scherr, and E. Redish, in Transfer of Learning from a Modern Multidisciplinary Perspective, edited by J. P. Mestre (Information Age Publ, Greenwich, CT, 2005). p. 89.

[12] M. R. Stetzer, P. van Kampen, P. S. Shaffer, and L. C. McDermott, New insights into student understanding of complete circuits and the conservation of current, Am. J. Phys. 81, 134 (2013).

[13] S. Johsua and J. J. Dupin, Schematic diagrams, representations and type of reasoning in basic electricity, in Aspects of Understanding Electricity, Proceedings of an International Workshop, edited by R. Duit, C. v. Rhöneck, and W. Jung (Schmidt und Klaunig, Kiel, 1985), p. 129.

[14] C. v. Rhöneck, Naturwissenschaften im UnterrichtPhysik/Chemie 10, 10 (1986).

[15] R. Cohen, B. Eylon, and U. Ganiel, Potential difference and current in simple electric circuits: A study of students' concepts, Am. J. Phys. 51, 407 (1983).

[16] P. V. Engelhardt and R. J. Beichner, Students' understanding of direct current resistive electrical circuits, Am. J. Phys. 72, 98 (2004).

[17] D. Shipstone, Aspects of understanding electricity, in Proceedings of an International Workshop, edited by R. Duit, C. v. Rhöneck, and W. Jung (Schmidt und Klaunig, Kiel, 1985), p. 73.

[18] M. Caillot, Aspects of understanding electricity, in Proceedings of an International Workshop, edited by R. Duit, C. v. Rhöneck, and W. Jung (Schmidt und Klaunig, Kiel, 1985), p. 139.
[19] P. M. Heller and F. N. Finley, Variable uses of alternative conceptions: A case study in current electricity, J. Res. Sci. Teach. 29, 259 (1992).

[20] Sebastià and M. José, Cognitive mediators and interpretations of electric circuits, in Proceedings of the Third International Seminar on Misconceptions and Educational Strategies in Science and Mathematics, edited by Cornell University, Education Department (Cornell University, Ithaca, New York, 1993).

[21] P. S. Shaffer and L. C. McDermott, Research as a guide for curriculum development: An example from introductory electricity. Part II: Design of instructional strategies, Am. J. Phys. 60, 1003 (1992).

[22] L. C. McDermott and P. S. Shaffer, Tutorials in Introductory Physics (Prentice Hall, Upper Saddle River, N.J., 2002).

[23] L. C. McDermott, P. S. Shaffer, and M. L. Rosenquist, Physics by Inquiry. An Introduction to Physics and the Physical Sciences (Wiley, New York, 1996).

[24] K. Zuza et al., Towards a research program in designing and evaluating teaching materials: An example from dc resistive circuits in introductory physics, Phys. Rev. Phys. Educ. Res. 16, 020149 (2020).

[25] D. Psillos, A. Tiberghien, and P. Koumaras, Voltage presented as a primary concept in an introductory teaching sequence on DC circuits, Int. J. Sci. Educ. 10, 29 (1988).

[26] D. Gentner, Structure-mapping: A theoretical framework for analogy, Cogn. Sci. 7, 155 (1983).

[27] H. Schwedes and W.-G. Dudeck, Teaching electricity by help of a water analogy (how to cope with the need for conceptual change), in Research in Science Education in Europe (Taylor \& Francis, London, 1996), pp. 50-63, ISBN: 9780203985472.

[28] C. Gleixner, Einleuchtende Elektrizitätslehre mit Potential. Untersuchungen zu Lernprozessen in der elementaren Elektrizitätslehre LMU München, Dissertation 1998.

[29] M. S. Steinberg and C. L. Wainwright, Using models to teach electricity-The CASTLE project, Phys. Teach. 31, 353 (1993).

[30] J.-P. Burde and T. Wilhelm, Teaching electric circuits with a focus on potential differences, Phys. Rev. Phys. Educ. Res. 16, 020153 (2020).

[31] A. A. diSessa, M. Levin, and N. J. Brown, Knowledge and Interaction. A Synthetic Agenda for the Learning Sciences (Taylor and Francis, London, 2015).

[32] I. Halloun, Inventory of Basic Conceptions-DC Circuits (IBCDC) (PhysPort, 2007), https://www.physport.org/ assessments/assessment.cfm? $\mathrm{I}=96 \& \mathrm{~A}=\mathrm{IBCDC}$.

[33] D. Sokoloff, Electric Circuits Conceptual Evaluation (ECCE) (PhysPort, 1996), https://www.physport.org/ assessments/assessment.cfm? $\mathrm{I}=25 \& \mathrm{~A}=\mathrm{ECCE}$.

[34] H. Peşman and A. Eryılmaz, Development of a three-tier test to assess misconceptions about simple electric circuits, J. Educ. Res. 103, 208 (2010).

[35] P. Tamir, Some issues related to the use of justifications to multiple-choice answers, J. Biol. Educ. 23, 285 (1989).

[36] P. B. Griffard and J. H. Wandersee, The two-tier instrument on photosynthesis: What does it diagnose?, Int. J. Sci. Educ. 23, 1039 (2001). 
[37] F. Haslam and D. F. Treagust, Diagnosing secondary students' misconceptions of photosynthesis and respiration in plants using a two-tier multiple choice instrument, J. Biol. Educ. 21, 203 (1987).

[38] U. Di Scotti Uccio, A. Colantonio, S. Galano, I. Marzoli, F. Trani, and I. Testa, Design and validation of a two-tier questionnaire on basic aspects in quantum mechanics, Phys. Rev. Phys. Educ. Res. 15, 010137 (2019).

[39] See Supplemental Material at http://link.aps.org/ supplemental/10.1103/PhysRevPhysEducRes.17.020123 for the whole test and for item entry table with all item parameters.

[40] J. M. Linacre, A User's Guide to WINSTEPS, https://www .winsteps.com/manuals.htm.

[41] K. Neumann, T. Viering, W. J. Boone, and H. E. Fischer, Towards a learning progression of energy, J. Res. Sci. Teach. 50, 162 (2013).

[42] D. Salibašić Glamočić, V. Mešić, K. Neumann, A. Sušac, W. J. Boone, I. Aviani, E. Hasović, N. Erceg, R. Repnik, and V. Grubelnik, Maintaining item banks with the Rasch model: An example from wave optics, Phys. Rev. Phys. Educ. Res. 17, 010105 (2021).

[43] M. Planinic, L. Ivanjek, A. Susac, and Z. Milin-Sipus, Comparison of university students' understanding of graphs in different contexts, Phys. Rev. ST Phys. Educ. Res. 9, 020103 (2013).

[44] M. Planinic, L. Ivanjek, and A. Susac, Rasch model based analysis of the Force Concept Inventory, Phys. Rev. ST Phys. Educ. Res. 6, 010103 (2010).
[45] M. Planinic, W. J. Boone, R. Krsnik, and M. L. Beilfuss, Exploring alternative conceptions from Newtonian dynamics and simple DC circuits: Links between item difficulty and item confidence, J. Res. Sci. Teach. 43, 150 (2006).

[46] V. Mešić et al., Measuring students' conceptual understanding of wave optics: A Rasch modeling approach, Phys. Rev. Phys. Educ. Res. 15, 010115 (2019).

[47] W. J. Boone, J. R. Staver, and M. S. Yale, Rasch Analysis in the Human Sciences (Springer, Dordrecht, 2014).

[48] T. G. Bond and C. M. Fox, Applying the Rasch model: Fundamental measurement in the human sciences, J. Educ. Measure. 40, 185 (2003).

[49] M. Planinic, W. J. Boone, A. Susac, and L. Ivanjek, Rasch analysis in physics education research: Why measurement matters, Phys. Rev. Phys. Educ. Res. 15, 020111 (2019).

[50] X. Liu, Using and Developing Measurement Instruments in Science Education. A Rasch Modeling Approach (Information Age, Greenwich, CT, 2010).

[51] Y. Xiao, J. Han, K. Koenig, J. Xiong, and L. Bao, Multilevel Rasch modeling of two-tier multiple choice test: A case study using Lawson's classroom test of scientific reasoning, Phys. Rev. Phys. Educ. Res. 14, 020104 (2018).

[52] J.-P. Burde et al., Evaluating Secondary School Students' Interest and Conceptual Understanding of Circuits, in Physics Education Research Conference Proceedings (2020), pp. 69-74, https://doi.org/10.1119/perc.2020.pr .Burde. 